\title{
Determination of reference values for salivary cortisol in healthy infants aged 0-12 months
}

\author{
Anouk L. Fastman, M.D. ${ }^{a}$, Valeria Schmoll, Biochemist ${ }^{b}$ and \\ Christian Boggio Marzet, M.D. ${ }^{a}$
}

\begin{abstract}
Introduction. Salivary cortisol is a useful tool as a biomarker of stress in pediatrics because it allows for non-invasive sampling. There is little information about its use in children, and no reference values for healthy infants have been reported in Argentina. Reference values should be established at each site as the basis for subsequent tests in infants, for whom salivary cortisol appears to be the most relevant objective tool to assess stress at present.

Objective. To determine reference values for salivary cortisol in healthy infants aged 0-12 months.
\end{abstract}

Methods. Descriptive, cross-sectional study that assessed morning salivary cortisol levels in healthy male and female infants aged 0-12 months that attended Hospital Pirovano for a health checkup between March 2017 and March 2018. Fasting saliva samples were collected between 8 and 9 a.m. and were processed using electrochemiluminescence. Results were reported as mean and standard deviation.

Results. A total of 140 infants were included, and 96 samples were collected. Mean morning salivary cortisol levels were $5.46 \mathrm{nmol} / \mathrm{L}$ (95\% confidence interval: 4.66-6.38), standard deviation: 2.15. No correlation to age was observed, so it was not necessary to divide the reference range into age groups. No significant differences were observed in terms of sex, gestational age, birth weight, type of delivery or type of feeding.

Conclusion. The reference range of morning salivary cortisol levels in healthy infants aged 0-12 months was reported.

Key words: reference values, salivary cortisol, infants.

E-mail address:

Anouk L. Fastman, MD: anoukfastman@ gmail.com

Funding: This study was funded with a research fellowship granted by the Argentine Society of Pediatrics for 2017 to Anouk Fastman, M.D.

http: / / dx.doi.org/10.5546/ aap.2020.eng.18

To cite: Fastman AL, Schmoll V, Boggio MarzetC. Determination of reference values for salivary cortisol in healthy infants aged 0-12 months. Arch Argent Pediatr 2020;118(1):18-24.

\section{INTRODUCTION}

Cortisol levels are considered a biological marker of stress because they measure activity at the hypothalamic-pituitary-adrenal axis (HPA axis), which is one of the main response systems in human biology. Until cortisol levels were first measured, in children, stress was assessed through the subjective observation of behavioral patterns and vital signs and vasomotor symptoms. ${ }^{1}$ Cortisol has been historically studied in blood,,$^{2-4}$ but it has been demonstrated that venipuncture itself leads to falsely high values. ${ }^{5}$ Therefore, salivary cortisol emerged as a reliable, useful, non-invasive tool especially relevant in pediatrics and large-scale studies. ${ }^{3,5,6}$

Salivary cortisol levels are currently used for the diagnosis of psychological, psychiatric, endocrine, and growth disorders, etc. ${ }^{4,6,7}$ It has also been widely used for the analysis of functional digestive disorders (defined as per the Rome IV criteria) and as a measure of impact of different therapeutic alternatives: ${ }^{9}$ placebo analgesia in functional and organic abdominal pain, ${ }^{10}$ probiotics in functional gastrointestinal disorders (FGIDs), massages for gastroesophageal reflux in infants, ${ }^{12}$ among others.

It is striking that there is little information available on the use of salivary cortisol in children, its reference values, and potential uses. Several studies have documented salivary cortisol levels in large populations of healthy individuals; mostly, preadolescents and adults. Few studies have established normal 
salivary cortisol levels in healthy infants ${ }^{13-18}$ and their outcomes cannot be compared for different reasons. For the time being, there is a single report on normal salivary cortisol levels in Argentina corresponding to newborn infants in the intensive care unit. ${ }^{19}$

There are apparently no reports about reference values in healthy infants up to 12 months of age; it is important to establish them at each site because assay sensitivity and specificity, as determined by antibody cross-reactivity with different steroid metabolites, differ widely. ${ }^{15}$ Therefore, in addition to a strict respect for preanalytical conditions, it is critical that each lab establishes its own analytical performance and its own reference ranges. ${ }^{7}$

Establishing country-specific reference values is the basis for subsequent studies on preand post-intervention salivary cortisol levels, especially in infants, for whom this seems to be the most important objective tool that can be used to assess stress at present. Therefore, the purpose of this study is to determine normal salivary cortisol levels in healthy infants aged 0-12 months.

\section{MATERIALS AND METHODS Design \\ Descriptive, cross-sectional study.}

\section{Population}

\section{Inclusion criteria}

Male and female infants aged 0-12 months who attended the Well-Child Office of Hospital General de Agudos "Dr. Ignacio Pirovano" for a health checkup (convenience, non-probability sampling) between March 2017 and March 2018 were included.

Exclusion criteria

- Exogenous administration of systemic corticosteroids during pregnancy and/or in the post-natal period.

- Endocrine disorders.

- Malnutrition.

- Febrile syndrome in the past $48 \mathrm{~h}$.

- Neurological developmental delay.

- Illegal drug use during pregnancy.

- Congenital malformations.

- Preterm infants and/or low birth weight for gestational age.

- Not signing the informed consent.

\section{Operational definition of outcome measures}

- Independent outcome measures:

Categorical: sex, type of delivery, type of feeding.

Continuous numerical: age, birth weight.

Discrete numerical: gestational age.

- Dependent outcome measure:

Salivary cortisol level at 8 a.m. (continuous numerical outcome measure). Measured using electrochemiluminescence.

A saliva sample was collected between 8 and 9 a.m. from all infants who met the inclusion criteria, without using saliva stimulants and after fasting for 30 minutes.

After performing pilot tests with different saliva sampling techniques, the simplest, most hygienic, painless, and reliable method was the one reported by E. Morelius et al., ${ }^{20}$ which consisted in two joined cotton swabs placed in the infant's mouth for a minute, upon carefully checking the mouth for eventual milk residues or erosions. Samples were sent immediately to the lab, where they were centrifuged and frozen at $-20{ }^{\circ} \mathrm{C}$ until processing using electrochemiluminescence (Cobas e601, Roche). The inter-assay coefficient of variation was $6 \%$.

\section{Statistical analysis}

Sample size calculation: Assuming a 0.05 type I error and a 0.8 type II error, to estimate the arithmetic mean of salivary cortisol in infants aged $0-12$ months and considering the $4 \mathrm{Z}_{\alpha} \mathrm{S} / \mathrm{W}$ equation, where $Z_{\alpha}=1.96(95 \%$ confidence interval $[\mathrm{CI}]), S$ (standard deviation) $=7 \mathrm{nmol} / \mathrm{L}$, $\mathrm{W}$ (estimated precision) $=3$, the minimum sample size was 84 subjects. ${ }^{21}$ An additional $10 \%$ was considered for insufficient volume samples.

With the Shapiro-Wilk test, it was observed that salivary cortisol results did not follow a normal distribution; therefore, this outcome measure was $\log$ transformed, as reported in multiple studies, ${ }^{2,13,16}$ and a normal distribution was finally achieved (Figure 1). No outliers were observed.

The Analyse-it software program was used for data processing. Results were reported as median, $\mathrm{CI}$ and $5^{\text {th }}$ and $95^{\text {th }}$ percentiles. Morning salivary cortisol levels and their relation to the dichotomous outcome measures sex and type of delivery were analyzed using a t test; birth weight and age distribution were analyzed using a correlation test; whereas type of feeding, with a one-way analysis of variance (ANOVA) with three levels (exclusive breastfeeding, infant formula, and mixed feeding). 


\section{Ethical aspects}

The study was approved by the Teaching and Research Committee (minutes no. 15, $11 / 3 / 16)$ and the Ethics Research Committee (minutes no. 119, 12/15/16) of Hospital General de Agudos "Dr. I. Pirovano." Provision DI2016-978-HGAIP. The principles of the Geneva Convention and the modified Declaration of Helsinki 2008 were followed. The study personnel committed to adhere to National Law no. 25326 for the Protection of Personal Information (Habeas Data). A written informed consent for study participation was obtained.

\section{RESULTS \\ Population analysis}

A total of 183 infants aged $0-12$ months attended the Well-Child Office between March 2017 and March 2018. Of these, 14 were excluded because they were using corticosteroids; 6 , due to malnutrition; 6 , recent febrile syndrome; 1 , illegal drug use during pregnancy; 9 , preterm birth and/ or low weight for gestational age; and 7 refused to give their informed consent.

Out of 140 healthy infants aged 0-12 months included in the study, morning salivary cortisol levels were determined in 96 . The other 44 cases

FIGURE 1. Normal distribution of salivary cortisol values. Log frequency histogram [SC] nmol/L

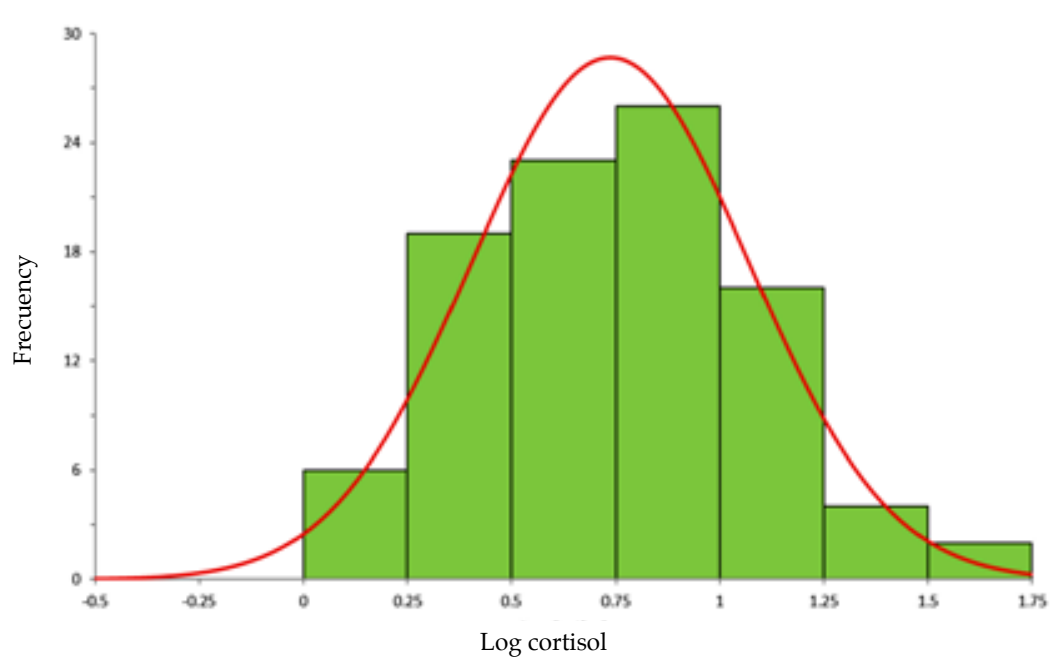

SC: salivary cortisol.

TABLE 1. Demographic characteristics

Characteristics of the population

Total (n)

Sex

Male, n (\%)

Female, $\mathrm{n}(\%)$

Age (months old), median, mean (min.-max.)

Birth weight $(\mathrm{g})$, median, mean (min.-max.)

Gestational age (weeks), median, mean (min.-max.)

Type of feeding

Exclusive breastfeeding, n (\%)

Infant formula, $\mathrm{n}(\%)$

Mixed feeding, $\mathrm{n}(\%)$

Type of delivery

Vaginal, n (\%)

C-section, $\mathrm{n}(\%)$
96

$57(59)$

$39(41)$

$6.07,6.17(0.9-12.07)$

$3540,3439(2500-4000)$

$39,39.22(37-41)$

$43(44.8)$

$27(28.1)$

$26(27.1)$

55 (57.3)

41 (42.7) 
corresponded to 8 samples below the limit of detection for the processing method and 36 insufficient volume samples. Of these, 17 (almost $50 \%$ ) were infants younger than 2 months in whom saliva sampling was known to be more difficult. Actually, no results were obtained in any infant younger than 26 days old. Sampling performance would have probably been better if citric acid had been used as a salivary secretion stimulant, as reported in the bibliography. However, it has not been demonstrated that citric acid does not interfere with measurements and even Roche, the manufacturer, indicated in the package insert for the electrochemiluminescence that samples containing citric acid should not be used; therefore, we decided not to use it in pursuit of greater result reliability, even though we knew it would undermine performance.

Table 1 shows the data of the studied population. The sample was homogeneously distributed in terms of age, sex, gestational age, and type of delivery.

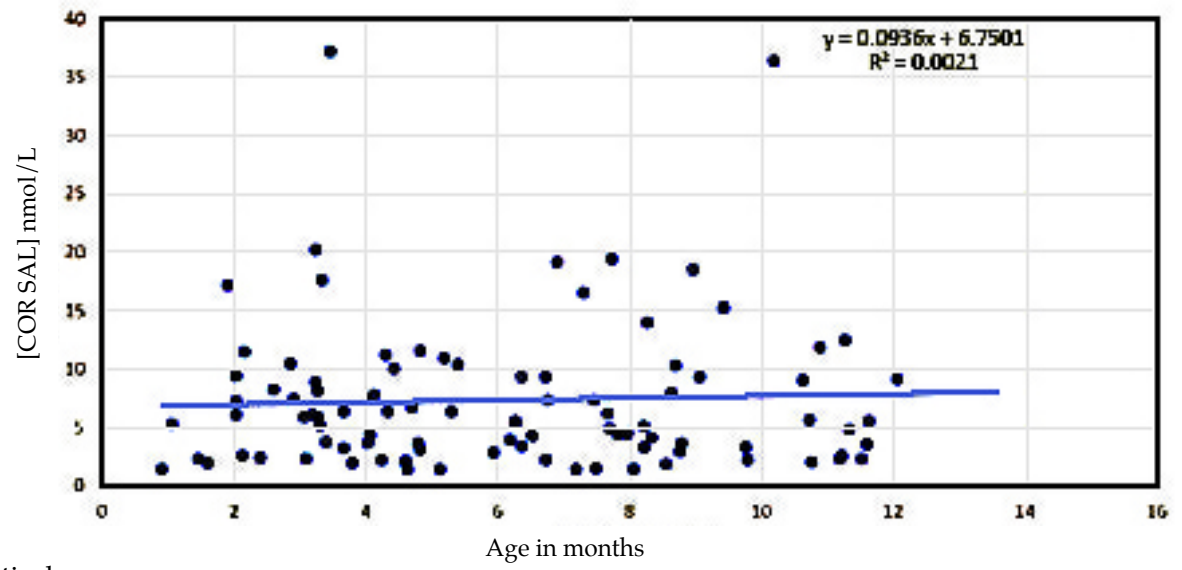

SC: salivary cortisol.

FIGURE 3. Salivary cortisol in relation to sex, type of delivery, and type of feeding

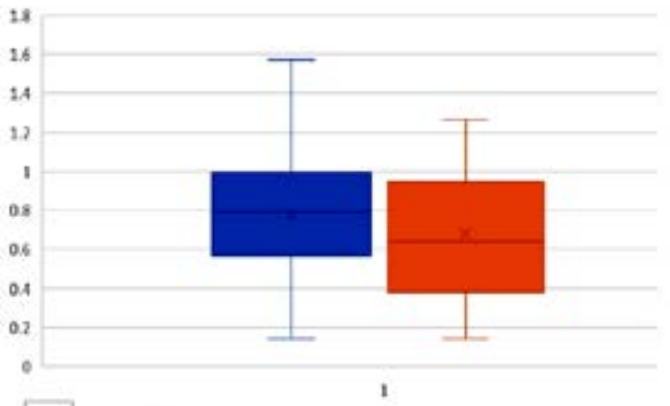

A $\quad$ Log salivary cortisol males $\mathbf{E}$ Log salivary cortisol females

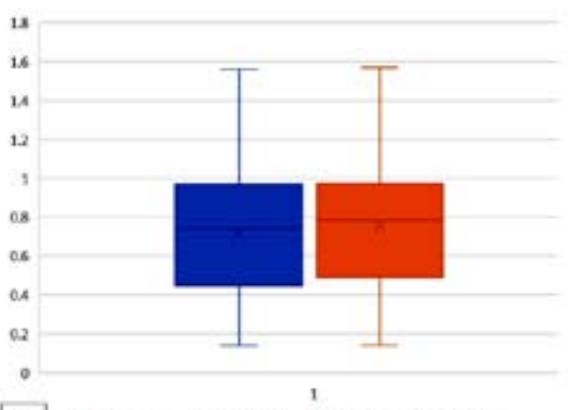

B $\quad$ Log cortisol vaginal delivery $\mathbf{E}$ Log cortisol C-section

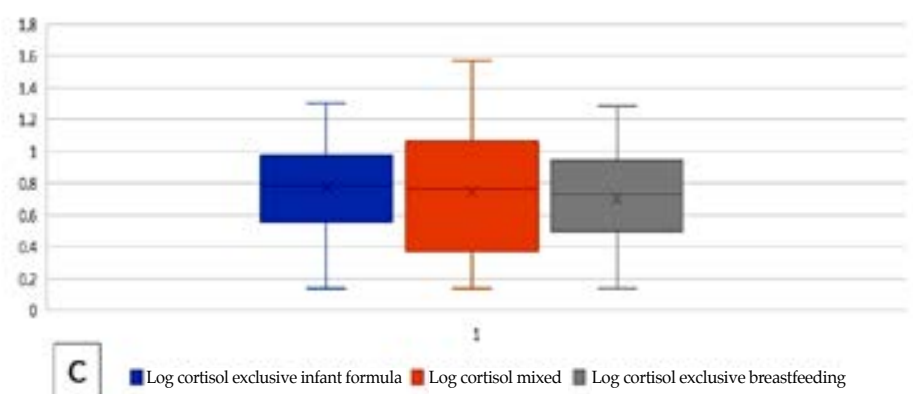




\section{Morning salivary cortisol measurement}

Mean morning salivary cortisol levels were $5.46 \mathrm{nmol} / \mathrm{L}$ (95 \% CI: 4.66-6.38), standard deviation (SD): 2.15 .

In relation to the study patients' age, salivary cortisol values showed a homogeneous distribution (Figure 2), with a trend line $y=0.0936$ $x+6.7501, R^{2}=0.0021$, without correlation among outcome measures. Therefore, the salivary cortisol outcome measure does not call for dividing the population into age groups, and the reference range is reported for the group of infants aged 0-12 months.

In relation to studied outcome measures, no significant differences were observed in terms of $\operatorname{sex}(p=0.16)$, type of delivery $(p=0.63)$, type of feeding: exclusive breastfeeding, infant formula, and mixed feeding ( $p=0.65)$ (Figure 3) or birth weight (trend line $\mathrm{y}=-0.0017 \mathrm{x}+13.122$; $\mathrm{R}^{2}=0.0196$ ) (Figure 4).

\section{DISCUSSION}

In the past, it was believed that young children did not feel pain, and the administration of analgesia during neonatal intensive care procedures was an exception. By 1980, it was agreed that they suffered experiences compatible with pain, opening up a new field of research to try and measure it. ${ }^{1}$ The use of scales including physiological parameters and behavioral responses became generalized, but they entailed the difficulty of inter-observer variability. Therefore, no tool has been universally adopted to assess pain in infants, and this is still a challenge worldwide.

Cortisol is an objective measurement for the assessment of stress, ${ }^{2-4}$ so it started to be studied based on blood cortisol levels. A drawback of this is that it may result in falsely high levels because venipuncture itself may activate the HPA axis and it is a costly, arduous, ${ }^{5}$ invasive test and, therefore, not useful for research in pediatrics.

Cortisol may also be measured in saliva, and it is a marker of an acute response to stress. Its advantages are multiple: sampling is simple and non-invasive, so it is useful for pediatric research, ${ }^{3}$ especially in infants due to the fact that it is impossible to know how they feel, ${ }^{6}$ it is useful for repeated measurements in short intervals; it may be performed in large populations (field studies); and it can be done in the subjects' natural environment (sampling done by a family member). ${ }^{5}$ It is also useful because it is not affected by protein binding or salivary flow and represents the biologically active fraction, so it is even more useful as a marker of adrenocortical function than serum cortisol. ${ }^{3}$

Multiple studies have related salivary cortisol to the diagnosis of psychiatric disorders, ${ }^{6}$ Cushing syndrome, adrenal insufficiency, and other diseases. ${ }^{4,7}$ Several studies have demonstrated that children with psychological disorders, obesity, and emotional deficiencies produce higher salivary cortisol levels, and it has been proposed that high levels might have an impact on their growth. In addition, they may cause arterial hypertension, immunosuppression, delayed wound healing, reduced effect of anesthetics, etc.

However, salivary cortisol would be most useful in conditions where symptoms cannot be easily objectified, such as functional gastrointestinal disorders (FGIDs). These account

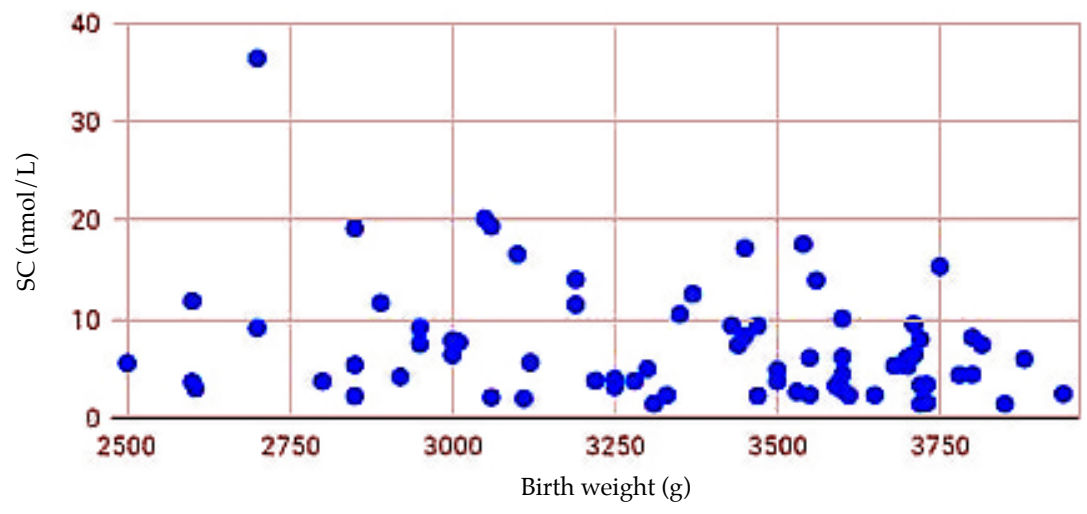

SC: salivary cortisol. 
for the most common reason for consultation at all ages.

According to the Rome IV criteria, FGIDs in infants and young children include a variable combination of chronic or recurrent symptoms that frequently depend on age and cannot be explained by structural or biochemical abnormalities. Its clinical expression varies with child's age and stage of physiological, autonomic, emotional, and intellectual development. When children acquire the verbal skills necessary to report pain, a predominant FGID is more easily diagnosed. ${ }^{8}$

Excessive crying is one of the most stressful problems in the first three months of life. There is no scientific evidence to demonstrate that the so-called "baby colic" is related to an organic pathology, and there is no validated treatment available for it. It would be very useful to establish if any of the commonly implemented measures or even any drug is capable of reducing stress in infants and dramatically improving their quality of life. Other FGIDs in infants and young children include infant regurgitation, cyclic vomiting syndrome, rumination syndrome, functional diarrhea, infant dyschezia, and functional constipation. All these conditions worsen the quality of life, cause difficulties in social adaptation, parental anxiety, and problems in the physician-patient relation due to the diagnostic and therapeutic difficulties involved. ${ }^{8}$

A reference range for salivary cortisol in healthy infants will be a very useful tool for the assessment of children with potential FGIDs. It has been previously mentioned that it is important for each site to have its own reference values according to their own processing and sample collection techniques. Although most studies describe similar results, several publications have shown very dissimilar results. The details of these studies are described in the Annex.

In relation to differences by sex, results are consistent with the worldwide bibliography, ${ }^{14,16,17}$ so the reference range has been standardized for both boys and girls.

In terms of the type of feeding, few studies have assessed morning salivary cortisol in relation to this outcome measure. A study published by Yang Cao et al., in $2009,{ }^{24}$ proposed that exclusively breastfed children had a morning salivary cortisol level that was $40 \%$ higher than those fed with infant formula. However, studies are not comparable. Although their sample size was larger and that serial samples were collected to compare salivary cortisol over time, that study did not report on the sample collection technique or sampling time, and they were processed with a different method (immunoaffinity column array). Besides, they did not consider children receiving mixed feeding, who in this study accounted for $30 \%$ of all subjects. Further studies are required to clarify this topic.

In relation to the type of delivery, N. M. Miller et al., in 2005, ${ }^{25}$ and A. Chis et al., in 2017, ${ }^{26}$ reported that infants born via C-section had lower salivary cortisol levels than those born via vaginal delivery. However, results are not comparable to those of this study for different reasons. Each of those studies used a different sample collection method (Salivette and SalivaBio Infant's Swab, by Salimetrics, respectively) and a different processing method (radioimmunoassay and enzyme immunoassay) than this study. In addition, in those studies, samples were collected immediately after birth and during the neonatal period, and this study included infants up to 12 months old. Most likely, the effect of the type of delivery does not have the same influence on salivary cortisol levels over time. Prospective studies should be designed to assess children from birth until at least 1 year old to elucidate this matter.

The results are consistent with those reported worldwide and may be used to diagnose and monitor different conditions and, above all, to extend the field of research and assess the impact of stress on infants with different diagnostic tests and therapeutic measures.

\section{CONCLUSION}

This is the first study that has established reference ranges for morning salivary cortisol levels in healthy infants aged 0-12 months at a general acute care hospital in the Autonomous City of Buenos Aires. No significant differences were observed in terms of sex, gestational age, birth weight, type of delivery or type of feeding.

\section{REFERENCES}

1. Herrington C, Olomu I, Geller S. Salivary Cortisol as Indicators of Pain in Preterm Infants. Clin Nurs Res. 2004; 13(1):53-68.

2. Kobayashi H, Miyazaki Y. Distribution characteristics of salivary cortisol measurements in a healthy young male population. J Physiol Anthropol. 2015; 34:30.

3. Hellhammer D, Wüst S, Kudielka B. Salivary cortisol as a biomarker in stress research. Psychoneuroendocrinology. 2009; 34(2):163-71.

4. Aguilar Cordero M, Sánchez López A, Mur Villar N, García Gracía I, et al. Cortisol salival como indicador de estrés fisiológico en niños y adultos: revisión sistemática. Nutr Hosp. 2014; 29(5):960-8. 
5. Kirschbaum C, Hellhammer D. Salivary cortisol. In Fink G (ed.). Encyclopedia of stress. San Diego: Academic Press. 2000; 3:379-84.

6. Papanicolaou D, Mullen N, Kyrou I, Nieman L. Nighttime salivary cortisol: a useful test for the diagnosis of Cushing's syndrome. J Clin Endocrinol Metab. 2002; 87(10):4515-21.

7. Maidana $\mathrm{P}$, Bruno $\mathrm{O}$, Mesch V. Medición de cortisol y sus fracciones: Una puesta al día. Medicina (B Aires). 2013; 73(6):579-84.

8. Benninga M, Nurko S, Faure C, Hyman P, et al. Childhood Functional Gastrointestinal Disorders: Neonate/Toddler. Gastroenterology. 2016; 150(6):1443-55.e2.

9. Törnhage CJ, Alfvén G. Diurnal salivary cortisol concentration in school-aged children: increased morning cortisol concentration and total cortisol concentration negatively correlated to body mass index in children with recurrent abdominal pain of psychosomatic origin. J Pediatr Endocrinol Metab. 2006; 19(6):843-54.

10. Schmid J, Langhorst J, GaB F, Theysohn N, et al. Placebo analgesia in patients with functional and organic abdominal pain: a fMRI study in IBS, UC and healthy volunteers. Gut. 2014; 64(3):418-27.

11. Urita $Y$, Goto M, Watanabe T, Matanabe M, et al. Continuous consumption of fermented milk containing Bifidobacterium bifidum YIT 10347 improves gastrointestinal and psychological symptoms in patients with functional gastrointestinal disorders. Biosci Microbiota Food Health. 2015; 34(2):37-44.

12. Neu M, Pan Z, Workman R, Marcheggiani-Howard C, et al. Benefits of massage therapy for infants with symptoms of gastroesophageal reflux disease. Biol Res Nurs. 2014; 16:38797.

13. Silva M, Mallozi M, Ferrari G. Salivary cortisol to assess the hypothalamic-pituitary-adrenal axis in healthy children under 3 years old. J Pediatr (Rio J). 2007; 83(2):121-6.

14. Ivars K, Nelson N, Theodorsson A, Theodorsson E, et al. Development of salivary cortisol circadian rhythm and reference intervals in full-term infants. PloS One. 2015; 10(6): 0129502.

15. Kiess W, Pfaeffle R. Steroid analysis in saliva: a noninvasive tool for pediatric research and clinical practice. $J \mathrm{Pe}$ diatr (Rio J). 2007; 83(2):97-9.
16. Gröschl M, Rauh M, Dörr H. Circadian rhythm of salivary cortisol, $17 \alpha$-hydroxyprogesterone, and progesterone in healthy children. Clin Chem. 2003; 49(10):1688-91.

17. Törnhage CJ. Reference values for morning salivary cortisol concentrations in healthy school-aged children. $\mathrm{J} \mathrm{Pe}$ diatr Endocrinol Metab. 2002; 15(2):197-204.

18. Kiess W, Meidert A, Dressendörfer R, Schriever K, et al. Salivary cortisol levels throughout childhood and adolescence: relation with age, pubertal stage and weight. Pediatr Res. 1995; 37(4 Pt 1):502-6.

19. Forclaz MV, Moratto E, Pennisi A, Falco S, et al. Niveles de cortisol en la saliva y séricos en recién nacidos. Arch Argent Pediatr. 2017; 115(3):262-6.

20. Morelius E, Nelson N, Theodorsson E. Salivary cortisol and administration of concentrated oral glucose in newborn infants: improved detection limit and smaller sample volumes without glucose interference. Scand J Clin Lab Invest. 2004; 64(2):113-8.

21. Browner WS, Newman T, Hulley SB. Appendix 6D. In Hulley SB, Cummings SR, Browner WS, Grady D, et al. Designing clinical research: an epidemiologic approach. $4^{\text {th }} \mathrm{ed}$. Philadelphia, PA: Lippincott Williams \& Wilkins; 2013. Page 80.

22. Stenius F, Theorell T, Lilja G, Scheynius A, et al. Comparisons between salivary cortisol levels in six-months-olds and their parents. Psychoneuroendocrinology. 2008; 33(3):352-9.

23. Cao Y, Rao S, Phillips T, Umbach D, et al. Are Breastfed Infants more Resilient?-Feeding Method and Cortisol in Infants. J Pediatr. 2009; 154(3):452-4.

24. Miller R, Stalder T, Jarczok M, Almeida D, et al. The CIRCORT database: Reference ranges and seasonal changes in diurnal salivary cortisol derived from a meta-dataset comprised of 15 field studies. Psychoneuroendocrinology. 2016; 73:16-23.

25. Miller NM, Fisk NM, Modi N, Glover V. Stress responses at birth: determinants of cord arterial cortisol and links with cortisol response in infancy. BJOG. 2005; 112(7):921-6.

26. Chis, A, Vulturar R, Andreica S, Prodan A, et al. Behavioral and cortisol responses to stress in newborn infants: Effects of mode of delivery. Psychoneuroendocrinology. 2017; 86:203-8. 
ANNEX

Studies on salivary cortisol levels

\begin{tabular}{|c|c|c|c|c|c|c|}
\hline Author & Year and origin & $\mathbf{N}$ & Age range & Outcome & Sampling & Processing \\
\hline Kiess $^{18}$ & 1995 Germany & 10 & $0-12 \mathrm{mo}$ & $13.7 \mathrm{nmol} / \mathrm{L}(1.4-81.3)$ & Suction pipette & $\begin{array}{l}\text { Radioimmunoassay } \\
\text { and DELFIA }\end{array}$ \\
\hline Groschl $^{16}$ & 2003 Germany & $\begin{array}{l}13 \\
17\end{array}$ & $\begin{array}{l}0-1 \mathrm{mo} \\
1-12 \mathrm{mo}\end{array}$ & $\begin{array}{l}34.5 \mathrm{nmol} / \mathrm{L}, \text { SD } 8.5 \\
24.3 \mathrm{nmol} / \mathrm{L}, \text { SD } 12\end{array}$ & $\begin{array}{l}\text { Modified } \\
\text { pacifier }\end{array}$ & Radioimmunoassay \\
\hline Silva ${ }^{13}$ & 2007 Brazil & 91 & $45 \mathrm{~d}-36 \mathrm{mo}$ & $\begin{array}{l}557.86 \mathrm{nmol} / \mathrm{L} \\
\text { (range: } 76.88-1620.08 \mathrm{nmol} / \mathrm{L} \text { ) }\end{array}$ & Saliva aspiration & Radioimmunoassay \\
\hline Stenius $^{22}$ & 2008 Sweden & 49 & $6 \mathrm{mo}$ & $19.9 \pm 23.6 \mathrm{nmol} / \mathrm{L}($ mean $\pm \mathrm{SD})$ & Braided cottonrolls & Radioimmunoassay \\
\hline $\mathrm{Cao}^{23}$ & 2009 USA & $\begin{array}{l}120 \mathrm{EBF} \\
239 \mathrm{IF}\end{array}$ & $0-12 \mathrm{mo}$ & $\begin{array}{l}-8.66 \mathrm{mcg} / \mathrm{dL}(239 \mathrm{nmol} / \mathrm{L}) \\
(\text { median})(\mathrm{EBF}) \\
-6.20 \mathrm{mcg} / \mathrm{dL}(171 \mathrm{nmol} / \mathrm{L})(\mathrm{IF})\end{array}$ & Not specified & $\begin{array}{l}\text { Immunoaffinity } \\
\text { column array }\end{array}$ \\
\hline Ivars $^{14}$ & 2015 Sweden & $\begin{array}{l}130 \text { children } \\
\text { (8800 samples) }\end{array}$ & $1-12$ mo & $\begin{array}{l}1 \mathrm{mo:} 5.1 \mathrm{nmol} / \mathrm{L}(\mathrm{Q} 1-\mathrm{Q} 32.8-8.2) \\
12 \mathrm{mo:} 10.9 \mathrm{nmol} / \mathrm{L}(\mathrm{Q} 1-\mathrm{Q} 35.9-14.4)\end{array}$ & Not reported & Radioimmunoassay \\
\hline Miller $^{24}$ & $\begin{array}{l}2016 \\
\text { Multicenter }\end{array}$ & $\begin{array}{l}18698 \\
15 \text { studies. } \\
\text { No. of children } \\
\text { not. reported }\end{array}$ & $\begin{array}{l}\text { Average: } \\
48.3 \text { yo } \\
\text { (range: }\end{array}$ & $\begin{array}{l}\text { Younger than } 5 \text { yo: } \\
\text { - median for girls: } 4.7 \mathrm{nmol} / \mathrm{L} \\
\text { (P5: } 1.3 \text { - P95: } 16.7) \\
\text { 0.5-98.5yo) } \\
\text { - median for boys: } 4.8 \mathrm{nmol} / \mathrm{L} \\
\text { (P5: } 1.4 \text { - P95: } 17.2)\end{array}$ & $\begin{array}{l}\text { Not } \\
\text { reported }\end{array}$ & $\begin{array}{l}\text { Not } \\
\text { reported }\end{array}$ \\
\hline
\end{tabular}

mo: months; d: days; P: percentile; SD: standard deviation; DELFIA: time-delayed fluorescence; EBF: exclusive breastfeeding; IF: infant formula; yo: years old. 